Supporting Information for

\title{
Contra-Thermodynamic Olefin Isomerization by Chain-Walking Hydrofunctionalization and Formal Retro-Hydrofunctionalization
}

\author{
Steven Hanna, Trevor W. Butcher, and John F. Hartwig* \\ Division of Chemical Sciences, Lawrence Berkeley National Laboratory, \\ Department of Chemistry, University of California, Berkeley, CA 94720, United States
}

Email: jhartwig@berkeley.edu 
Table of Contents

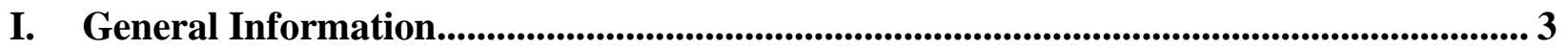

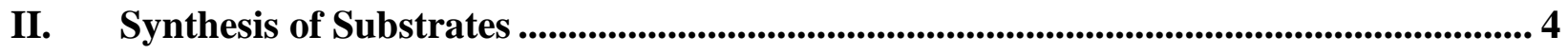

III. General Procedure for Contra-Thermodynamic Olefin Isomerization........................ 5

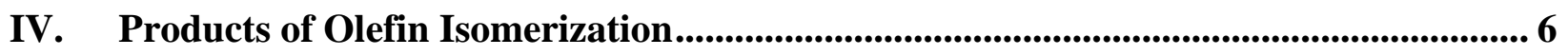

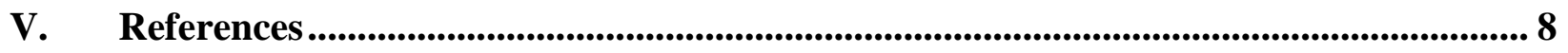

VI. ${ }^{1} \mathrm{H}$ NMR and ${ }^{13} \mathrm{C}$ NMR Spectra ............................................................................9 


\section{General Information}

All air-sensitive manipulations were conducted under an inert atmosphere in a nitrogenfilled glovebox or by standard Schlenk techniques. Unless stated otherwise, reagents and solvents were purchased from commercial suppliers and used without further purification. TLC plates were visualized by staining with $\mathrm{KMnO}_{4}$. All NMR spectra were recorded at the University of California, Berkeley NMR facility. Proton-NMR spectra were recorded on Bruker AVB-400, AVQ-400, AV-500, and AV-600 instruments with operating frequencies of 400, 400, 500, and 600 MHz, respectively, and Carbon-13 NMR spectra were recorded on a Bruker AV-600 instrument with a ${ }^{13} \mathrm{C}$ operating frequency of $151 \mathrm{MHz}$. Chemical shifts $(\delta)$ are reported in ppm relative to those of residual solvent signals $\left(\mathrm{CDCl}_{3} \delta=7.26\right.$ for ${ }^{1} \mathrm{H}$ NMR spectra and $\delta=77.16$ for ${ }^{13} \mathrm{C}$ NMR spectra). The following abbreviations were used in reporting NMR data: s, singlet; d, doublet; t, triplet; q, quartet; p, pentet; hept, heptet; m, multiplet. 


\section{Synthesis of Substrates}

\section{4-(tert-butyl)-1-methylcyclohex-1-ene}

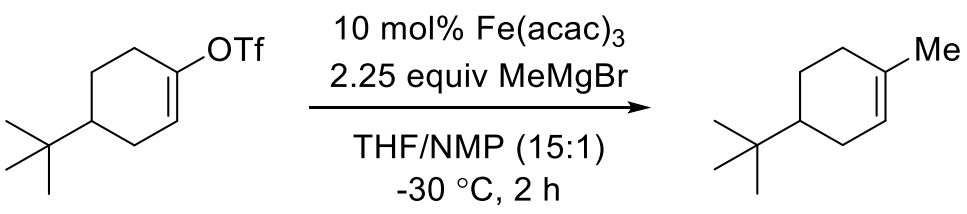

The following procedure was adapted from the literature. ${ }^{1}$ In a nitrogen-filled glove box, an ovendried $500 \mathrm{~mL}$ round bottomed flask equipped with a magnetic stir bar was charged with 4-(tertbutyl)cyclohex-1-en-1-yl trifluoromethanesulfonate ${ }^{2}$ (3.436 g, $12.00 \mathrm{mmol}, 1$ equiv) and THF (60 $\mathrm{mL})$. Anhydrous Fe(acac) 3 (423.6 mg, $1.199 \mathrm{mmol}, 10 \mathrm{~mol} \%$ ) was transferred to the flask with NMP (12 mL) and THF (120 mL). The reaction mixture was sealed with a septum, removed from the glove box, maintained under $\mathrm{N}_{2}$, and cooled to $-30{ }^{\circ} \mathrm{C}$ in an $o$-xylene/dry ice bath. Methyl magnesium bromide (3.0 M in $\mathrm{Et}_{2} \mathrm{O}, 9.00 \mathrm{~mL}, 27.0 \mathrm{mmol}, 2.25$ equiv) was added dropise. After complete addition of Grignard reagent, the reaction was stirred at $-30{ }^{\circ} \mathrm{C}$ for 2 hours. After this time, saturated aqueous $\mathrm{NH}_{4} \mathrm{Cl}$ was added $(50 \mathrm{~mL})$, the reaction mixture was warmed to room temperature, and the biphasic mixture was concentrated under reduced pressure. The resulting residue was dissolved in pentane $(100 \mathrm{~mL})$, washed with water $(8 \times 40 \mathrm{~mL})$, dried over sodium sulfate, and concentrated under reduced pressure. Column chromatography on silica gel (isocratic, pentane) afforded 4-(tert-butyl)-1-methylcyclohex-1-ene as a colorless liquid (1.379 g, 9.056 mmol, $75 \%$ yield). 


\section{General Procedure for Contra-Thermodynamic Olefin Isomerization}

Step 1: Chain-Walking Hydrosilylation

In a nitrogen-filled glove box, a heavy-walled Schlenk flask with a single opening (5-10 mL) equipped with a magnetic stir bar was charged with internal olefin ( 1 mmol, 1 equiv) and $2.0 \mu \mathrm{L}$ of a stock solution prepared by dissolving $100 \mathrm{mg} \mathrm{H}_{2} \mathrm{PtCl}_{6} \cdot 6 \mathrm{H}_{2} \mathrm{O}$ in $200 \mu \mathrm{L}$ of isopropanol $(\sim 1.0$ $\mathrm{mg} \mathrm{H}_{2} \mathrm{PtCl}_{6} \cdot 6 \mathrm{H}_{2} \mathrm{O}, 0.0020 \mathrm{mmol}, 0.20 \mathrm{~mol} \%$ ). The Schlenk flask was sealed with a Teflon plug, removed from the glove box, and cooled to $0^{\circ} \mathrm{C}$. Trichlorosilane ( $202 \mu \mathrm{L}, 2.00 \mathrm{mmol}, 2.00$ equiv) was added to the reaction mixture under $\mathrm{N}_{2}$, and the Schlenk flask was sealed and heated at 100 ${ }^{\circ} \mathrm{C}$ for $20 \mathrm{~h}$. After this time, the reaction mixture was cooled to room temperature and subjected to high vacuum (<1000 mtorr) for 15 minutes to remove excess $\mathrm{HSiCl}_{3}$. The Schlenk flask was then backfilled with $\mathrm{N}_{2}$ and transferred to a nitrogen-filled glove box.

\section{Step 2: Formal Retro-hydrosilylation}

Procedure A (for preparing 1,1-disubstituted olefins):

In a nitogen-filled glovebox and in the dark, a solution of iodine $(279.2 \mathrm{mg}, 1.100 \mathrm{mmol}, 1.100$ equiv) in dry DMF (2.50 mL) and anhydrous cesium fluoride powder (1.519 g, $10.00 \mathrm{mmol}, 10.00$ equiv) were added to the Schlenk flask containing crude alkyl trichlorosilane from step 1. The Schlenk flask was sealed, stirred at room temperature for 15 minutes, and heated with vigorous stirring at $100{ }^{\circ} \mathrm{C}$ for $20 \mathrm{~h}$ in the dark. After this time, the reaction mixture was carefully diluted with $\mathrm{CDCl}_{3}(5 \mathrm{~mL})$ in a fume hood, and trichloroethylene $(90.0 \mu \mathrm{L}, 1.00$ equiv) was added. An aliquot of this mixture was filtered through a $0.2 \mu \mathrm{m}$ PTFE syringe filter and analyzed by ${ }^{1} \mathrm{H}$ NMR spectroscopy.

Procedure B (for preparing monosubstituted olefins):

In a nitogen-filled glovebox and in the dark, a solution of iodine $(279.2 \mathrm{mg}, 1.100 \mathrm{mmol}, 1.100$ equiv) in dry DMF (4.00 mL) and anhydrous cesium fluoride powder (911.0 mg, $6.000 \mathrm{mmol}$, 6.000 equiv) were added to the Schlenk flask containing crude alkyl trichlorosilane from step 1. The Schlenk flask was sealed, stirred at room temperature for 15 minutes, and heated with vigorous stirring at $100{ }^{\circ} \mathrm{C}$ for $20 \mathrm{~h}$ in the dark. After this time, the reaction mixture was cooled to room temperature, and dry sodium tert-butoxide (480.5 mg, $5.000 \mathrm{mmol}, 5.000$ equiv) was added. The reaction mixture was stirred at room temperature for $20 \mathrm{~h}$ with protection from light. After this time, the reaction mixture was carefully diluted with $\mathrm{CDCl}_{3}(5 \mathrm{~mL})$ in a fume hood, and trichloroethylene $(90.0 \mu \mathrm{L}, 1.00$ equiv) was added. An aliquot of this mixture was filtered through a $0.2 \mu \mathrm{m}$ PTFE syringe filter and analyzed by ${ }^{1} \mathrm{H}$ NMR spectroscopy. 


\section{Products of Olefin Isomerization}

1-octene (3c)

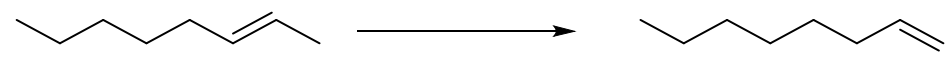

Prepared from $(E)$-2-octene $(112.2 \mathrm{mg}, 1.000 \mathrm{mmol})$ according to general procedure $\mathrm{B}$.

${ }^{1} \mathrm{H}$ NMR Yield: $65 \%$

\section{1-octene (3c)}

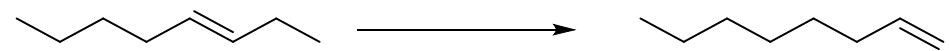

Prepared from $(E)-3$-octene $(110.9 \mathrm{mg}, 0.9946 \mathrm{mmol})$ according to general procedure B.

${ }^{1} \mathrm{H}$ NMR Yield: $69 \%$

\section{1-octene (3c)}

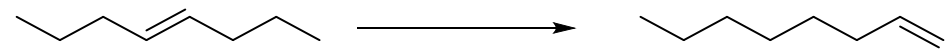

Prepared from $(E)$-4-octene $(111.6 \mathrm{mg}, 1.000 \mathrm{mmol})$ according to general procedure $\mathrm{B}$.

${ }^{1} \mathrm{H}$ NMR Yield: $66 \%$

\section{1-tetradecene (3f)}

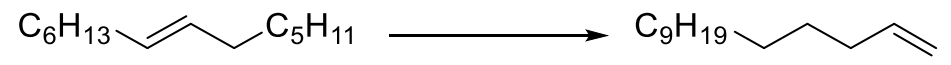

Prepared from $(E)$-7-tetradecene $(192.0 \mathrm{mg}, 0.978 \mathrm{mmol})$ according to general procedure B.

${ }^{1} \mathrm{H}$ NMR Yield $65 \%$

\section{1,6-heptadiene (3g)}

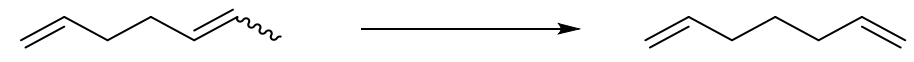

Prepared from 1,5-heptadiene $(95.3 \mathrm{mg}, 0.991 \mathrm{mmol})$ according to general procedure $\mathrm{B}$, with 4 equivalents $\mathrm{HSiCl}_{3}, 0.4 \mathrm{~mol} \% \mathrm{H}_{2} \mathrm{PtCl}_{6} \cdot 6 \mathrm{H}_{2} \mathrm{O}, 10$ equivalents of $\mathrm{CsF}, 2.2$ equivalents of $\mathrm{I}_{2}, 8 \mathrm{~mL}$ of $\mathrm{DMF}$, and 10 equivalents of $\mathrm{NaO} t-\mathrm{Bu}$.

${ }^{1} \mathrm{H}$ NMR Yield: $40 \%$ 


\section{1-(tert-butyl)-4-methylenecyclohexane (3h)}

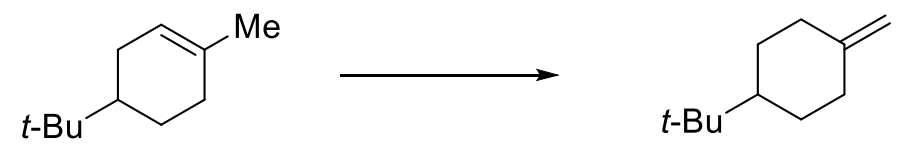

Prepared from 4-(tert-butyl)-1-methylcyclohex-1-ene (148.1 mg, $0.9726 \mathrm{mmol})$ according to general procedure A.

This procedure was also repeated on a 1 gram scale $(952.0 \mathrm{mg}, 6.252 \mathrm{mmol})$

${ }^{1} \mathrm{H}$ NMR Yield: $75 \%$ (150 mg scale)

${ }^{1} \mathrm{H}$ NMR Yield: $74 \%$ (1 g scale)

Isolation of olefin $3 \mathbf{h}$ : The NMR sample and crude reaction mixture were combined and carefully diluted with water $(100 \mathrm{~mL})$, and the resulting mixture was extracted with pentane $(3 \times 50 \mathrm{~mL})$. The combined organic layers were pink in color (residual iodine) and were decolorized by washing with $2 \mathrm{M}$ sodium thiosulfate $(3 \times 20 \mathrm{~mL})$. The combined layers were washed with water $(5 \times 20$ $\mathrm{mL})$ and brine $(1 \times 20 \mathrm{~mL})$, dried over sodium sulfate, and carefully concentrated in vacuo to afford a pale yellow liquid. Column chromatography on silica gel (isocratic, pentane, $\mathrm{R}_{\mathrm{f}} \sim 0.9$ ) followed by careful concentration in vacuo afforded pure 1-(tert-butyl)-4-methylenecyclohexane (3h) as a clear, colorless liquid $(79.0 \mathrm{mg}, 0.519 \mathrm{mmol}, 53 \%$ yield, small scale; $671.4 \mathrm{mg}, 4.409$ mmol, 71\%). The lower isolated yield relative to ${ }^{1} \mathrm{H}$ NMR yield on small scale is largely attributed to the volatility of the product (b.p. $=53{ }^{\circ} \mathrm{C}$ at 8 torr). ${ }^{3}$

${ }^{1} \mathrm{H}$ and ${ }^{13} \mathrm{C}$ NMR spectra of the product matched the literature. ${ }^{3}$

${ }^{1} \mathbf{H}$ NMR $\left(400 \mathrm{MHz}, \mathrm{CDCl}_{3}\right) \delta 4.58(\mathrm{t}, J=1.7 \mathrm{~Hz}, 2 \mathrm{H}), 2.33(\mathrm{~d}, J=13.6 \mathrm{~Hz}, 2 \mathrm{H}), 1.98(\mathrm{t}, J=13.3$ $\mathrm{Hz}, 2 \mathrm{H}), 1.86$ (d, $J=11.6 \mathrm{~Hz}, 2 \mathrm{H}), 1.20-0.96$ (m, 3H), 0.85 (s, 9H).

${ }^{13}$ C NMR $\left(151 \mathrm{MHz}, \mathrm{CDCl}_{3}\right) \delta 150.4,106.3,48.1,35.5,32.6,29.1,27.8$. 
Methylenecyclohexane (3i)<smiles>CC1C=CCCC1</smiles>

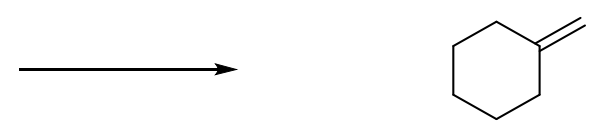

Prepared from 3-methylcyclohex-1-ene $(98.4 \mathrm{mg}, 1.02 \mathrm{mmol})$ according to general procedure A. ${ }^{1} \mathrm{H}$ NMR Yield: $58 \%$

\section{Methylenecyclohexane (3i)}<smiles>CC1CC=CCC1</smiles>

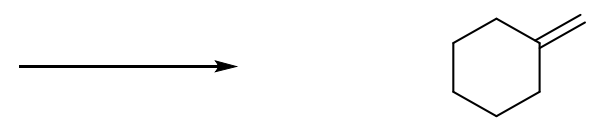

Prepared from 4-methylcyclohex-1-ene (95.4 mg, $0.992 \mathrm{mmol}$ ) according to general procedure A. ${ }^{1} \mathrm{H}$ NMR Yield: $58 \%$

\section{2,5-dimethylhex-1-ene (3k)}
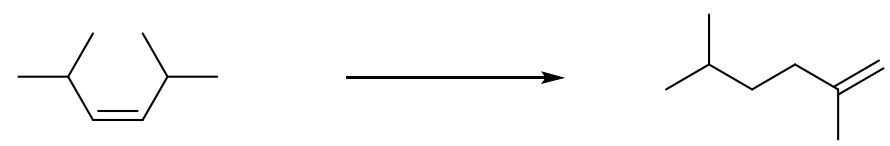

Prepared from (Z)-2,5-dimethylhex-3-ene (110.1 mg, $0.9811 \mathrm{mmol}$ ) according to general procedure A.

${ }^{1} \mathrm{H}$ NMR Yield: $49 \%$

\section{2,4,4-trimethylpent-1-ene (31)}<smiles>CC(C)=CC(C)(C)C</smiles>

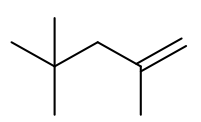

Prepared from 2,4,4-trimethylpent-2-ene (110.6 $\mathrm{mg}, 0.9856 \mathrm{mmol})$ according to general procedure A.

${ }^{1} \mathrm{H}$ NMR Yield: $56 \%$

\section{References}

1. Fürstner, A.; Hannen, P., Chemistry - A European Journal 2006, 12, 3006-3019.

2. Lim, B.-Y.; Jung, B.-E.; Cho, C.-G., Organic Letters 2014, 16, $4492-4495$.

3. $\quad$ Reid, W. B.; Watson, D. A., Organic Letters 2018, 20, 6832-6835. 
VI. ${ }^{1} \mathrm{H}$ NMR and ${ }^{13} \mathrm{C}$ NMR Spectra

Crude ${ }^{1} \mathrm{HNMR}$ spectra were recorded in $\mathrm{CDCl}_{3} / \mathrm{DMF}$ mixtures, causing some variability in chemical shifts.

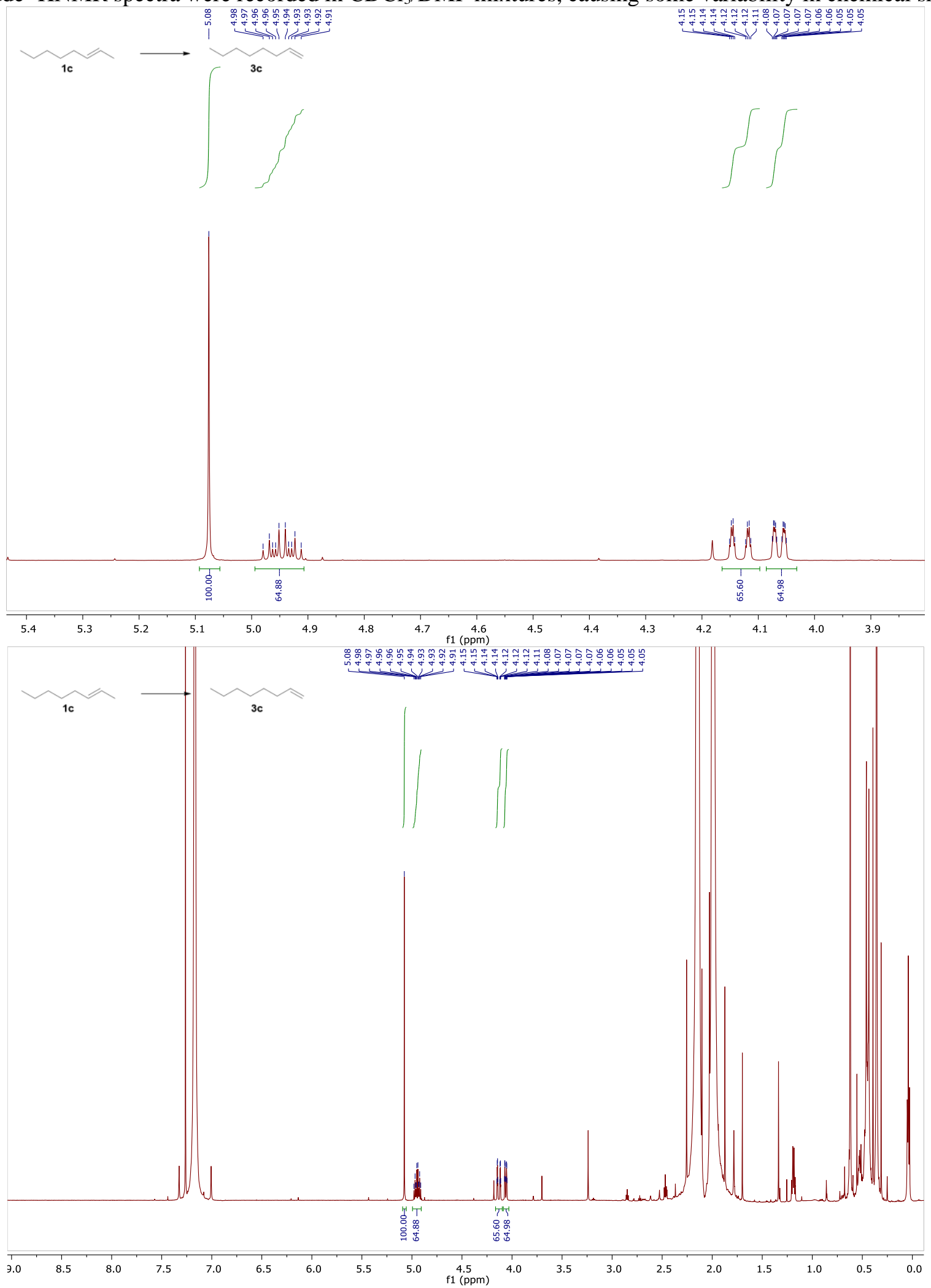




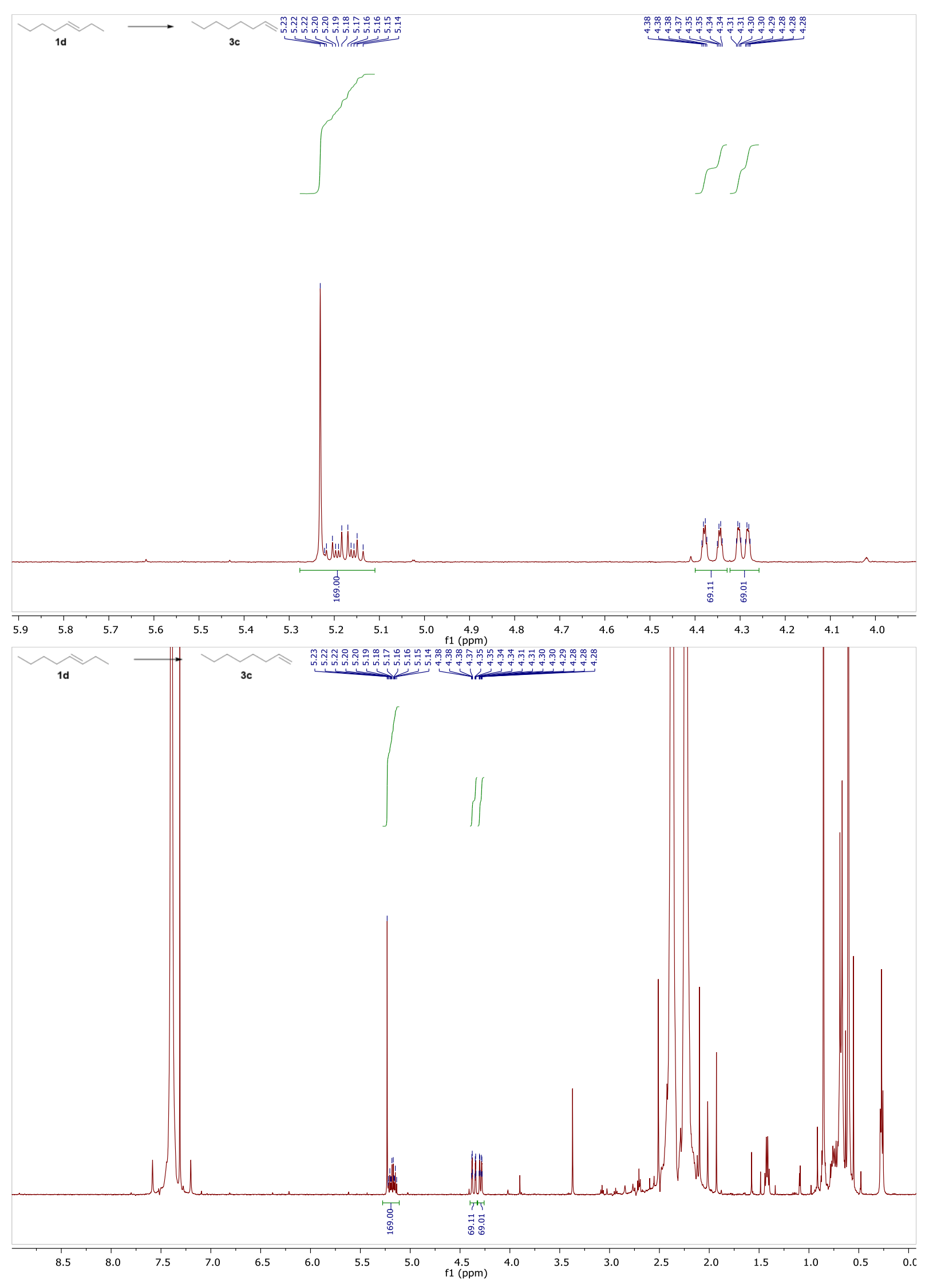




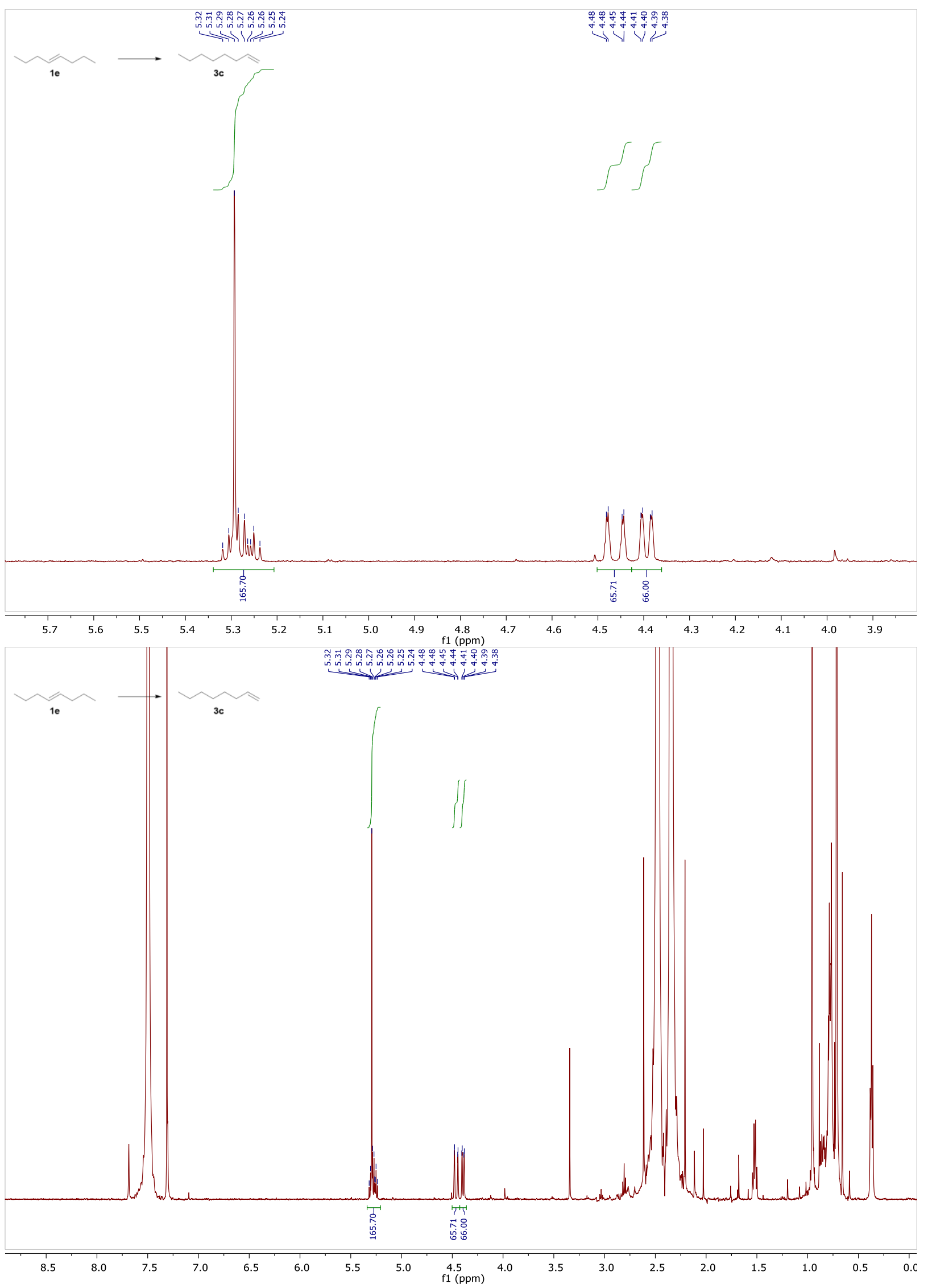




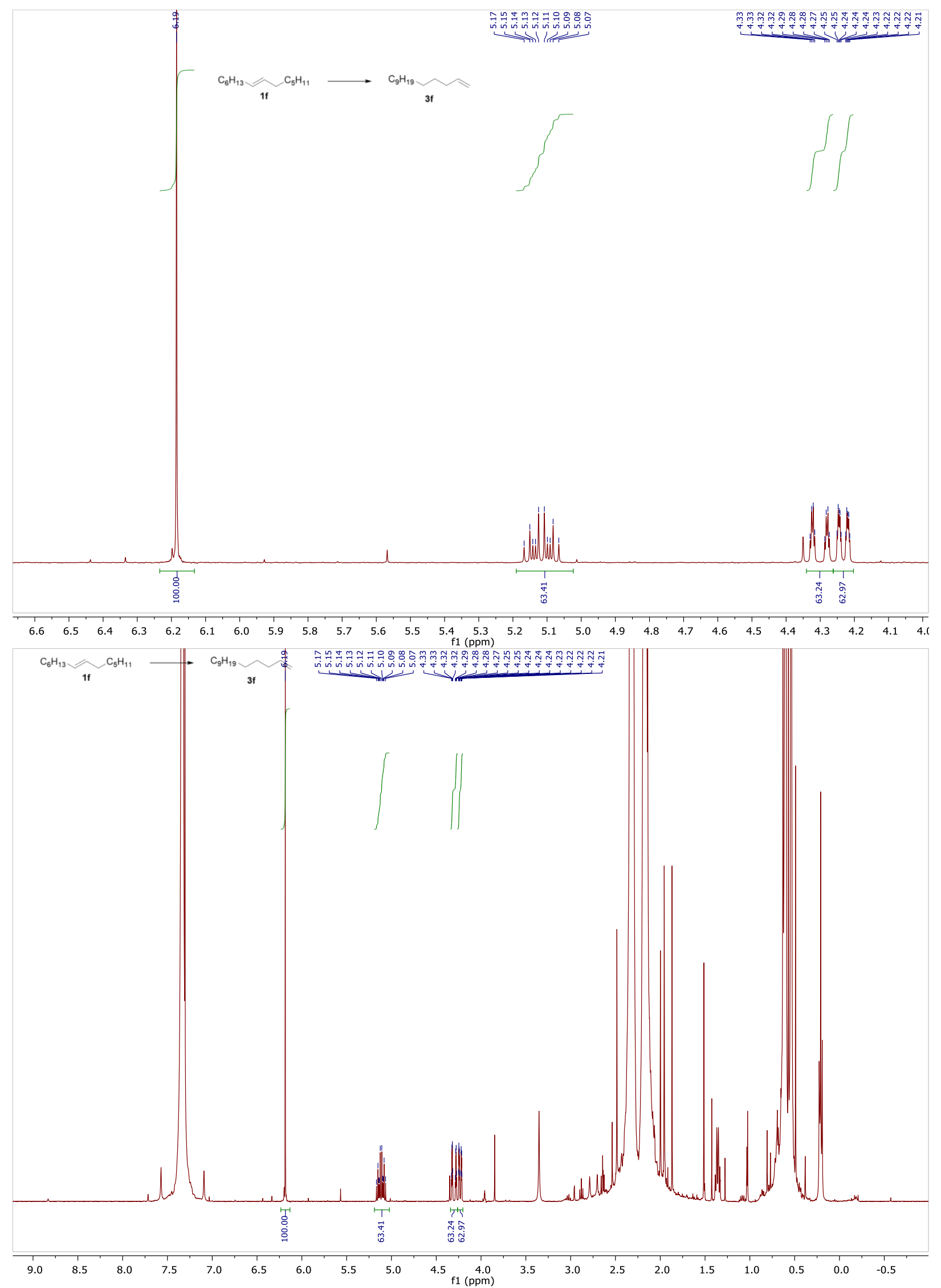




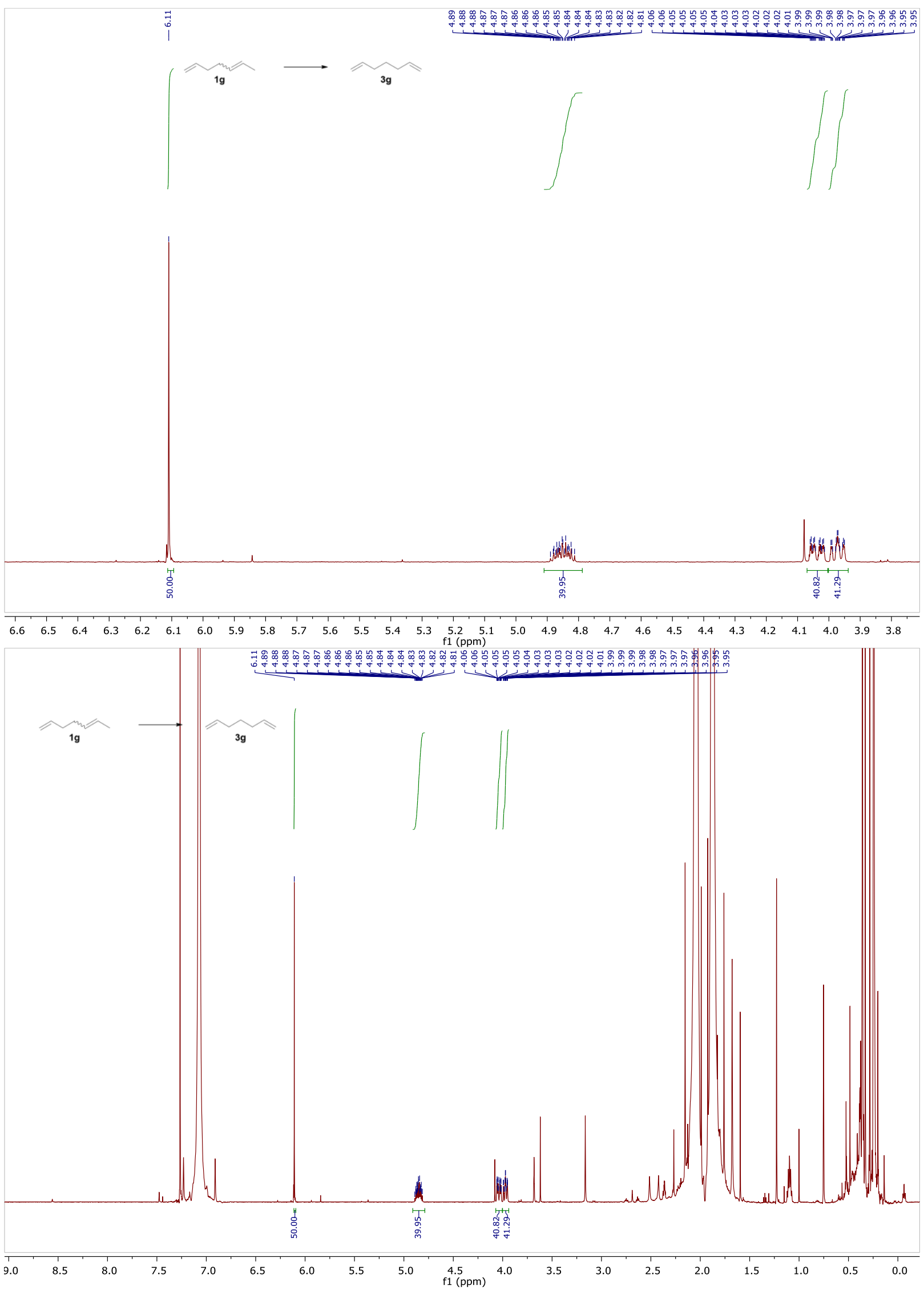




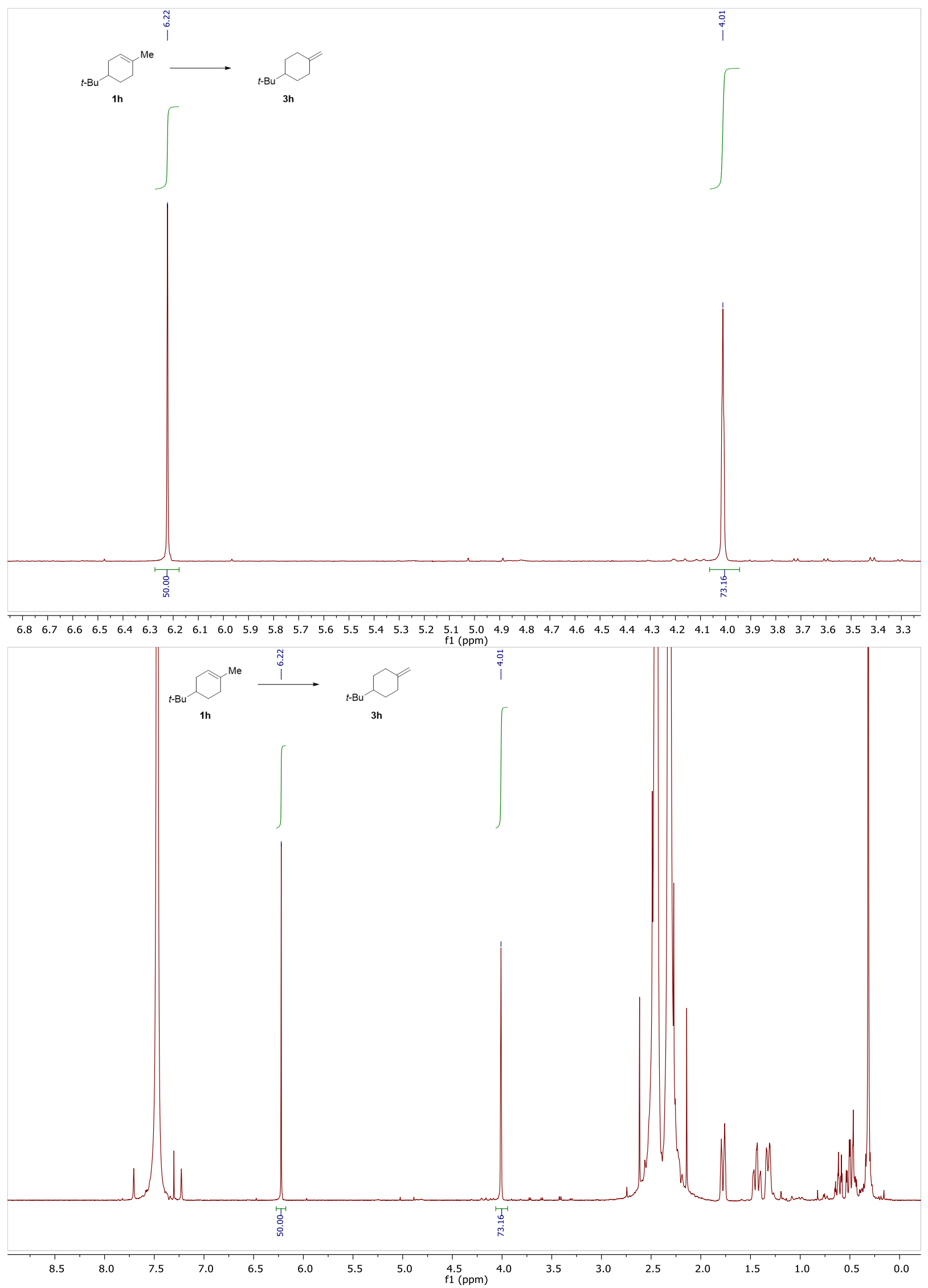




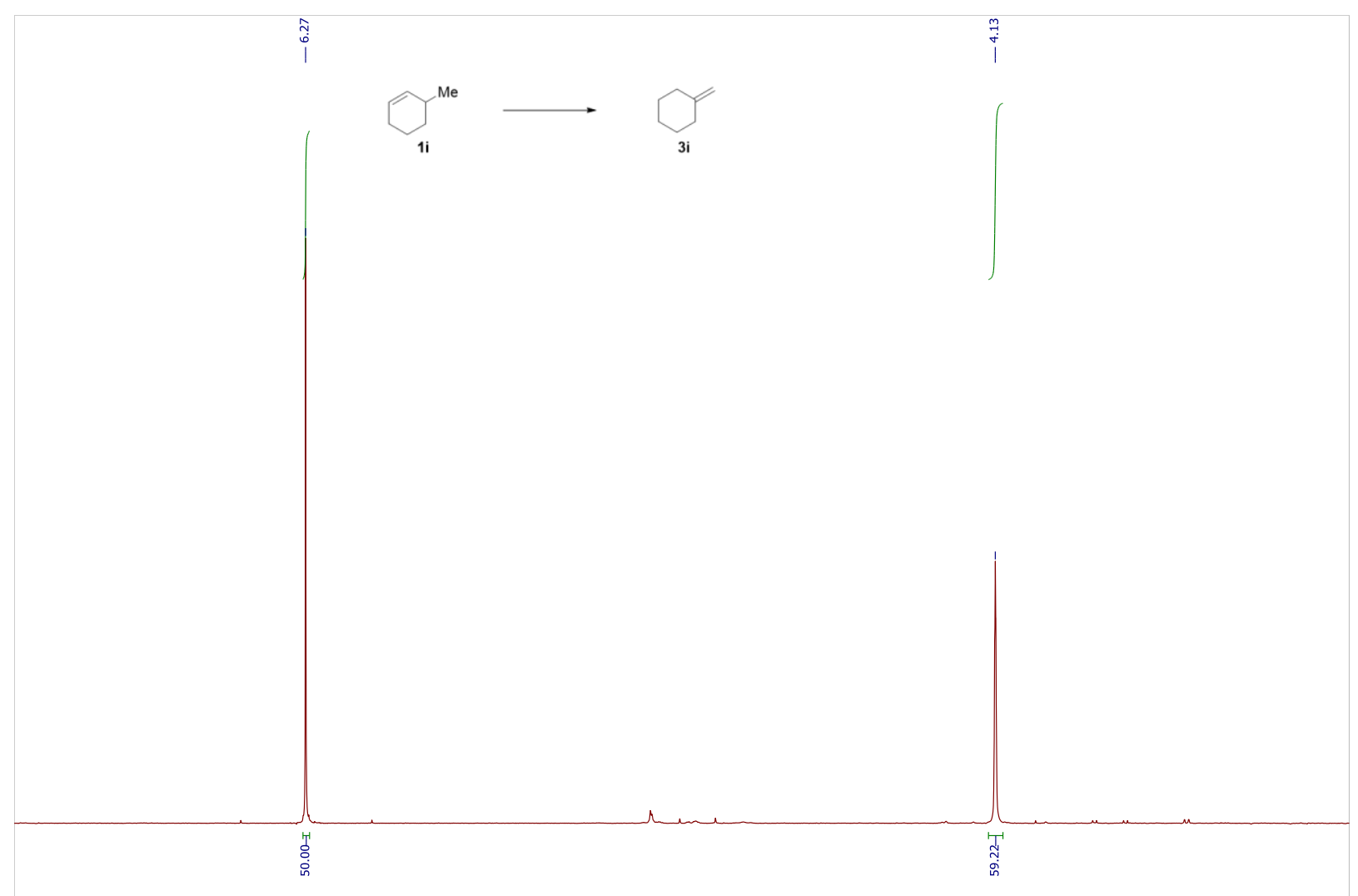

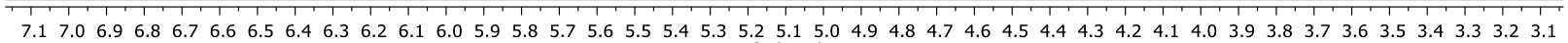

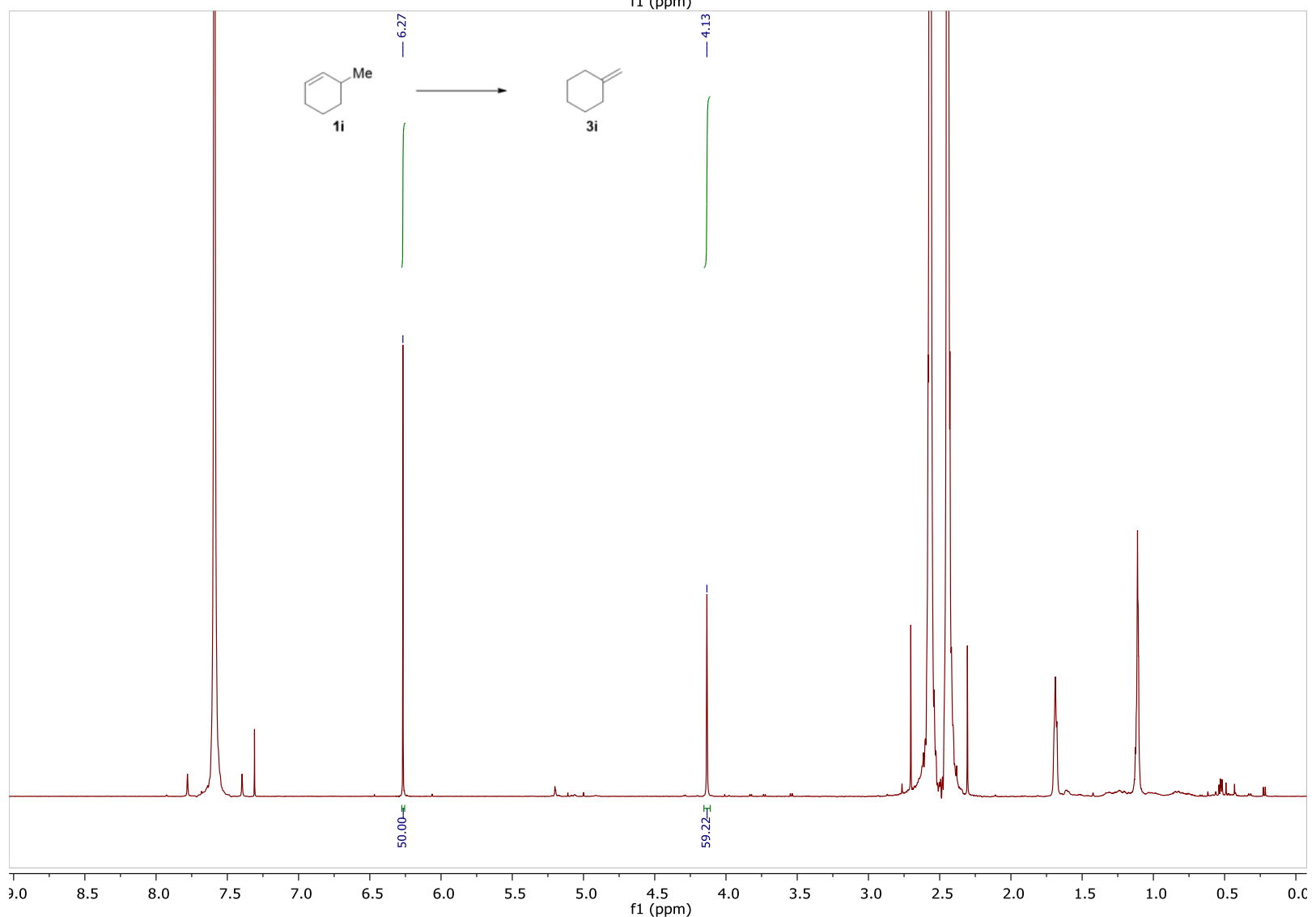




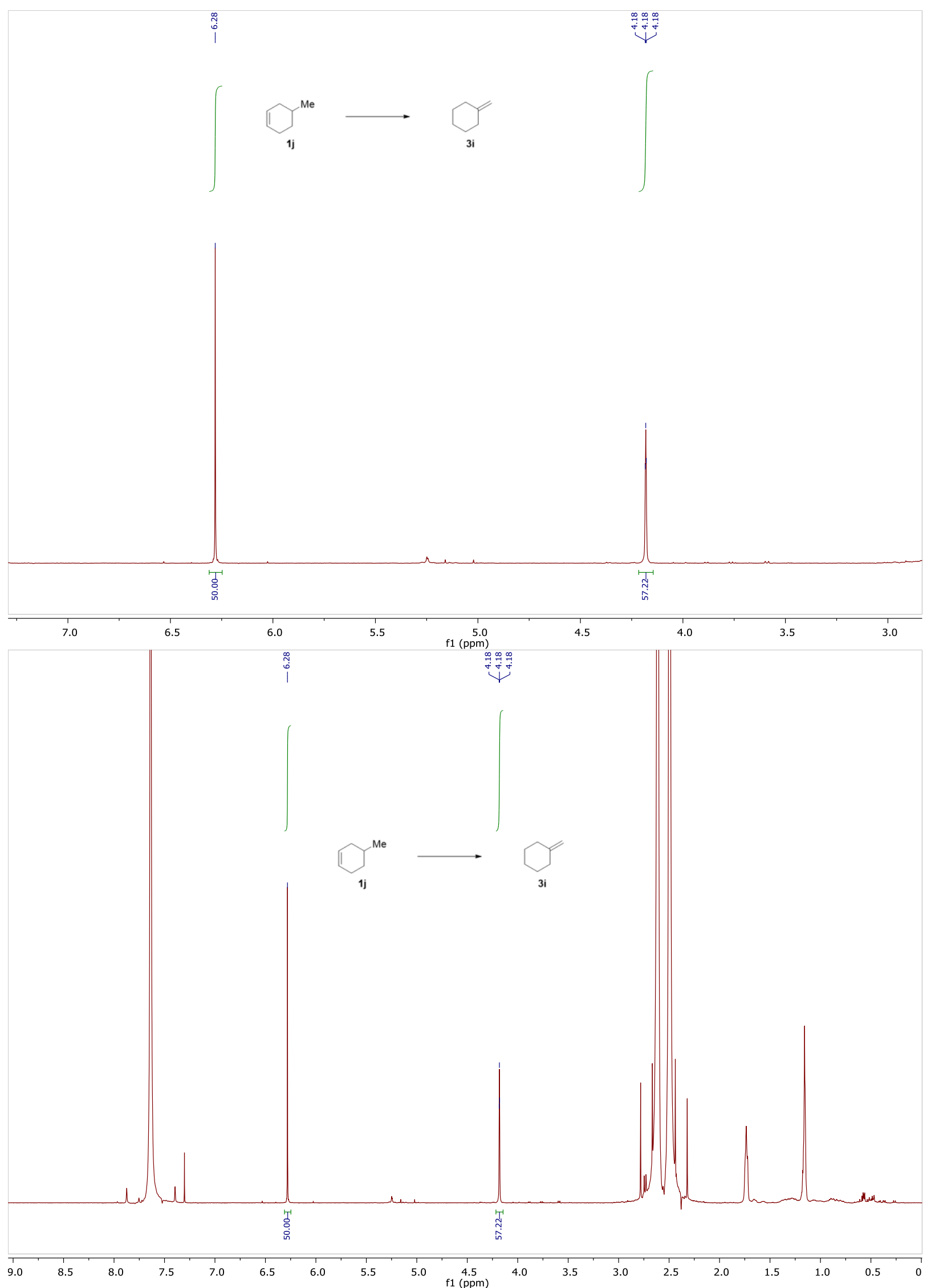




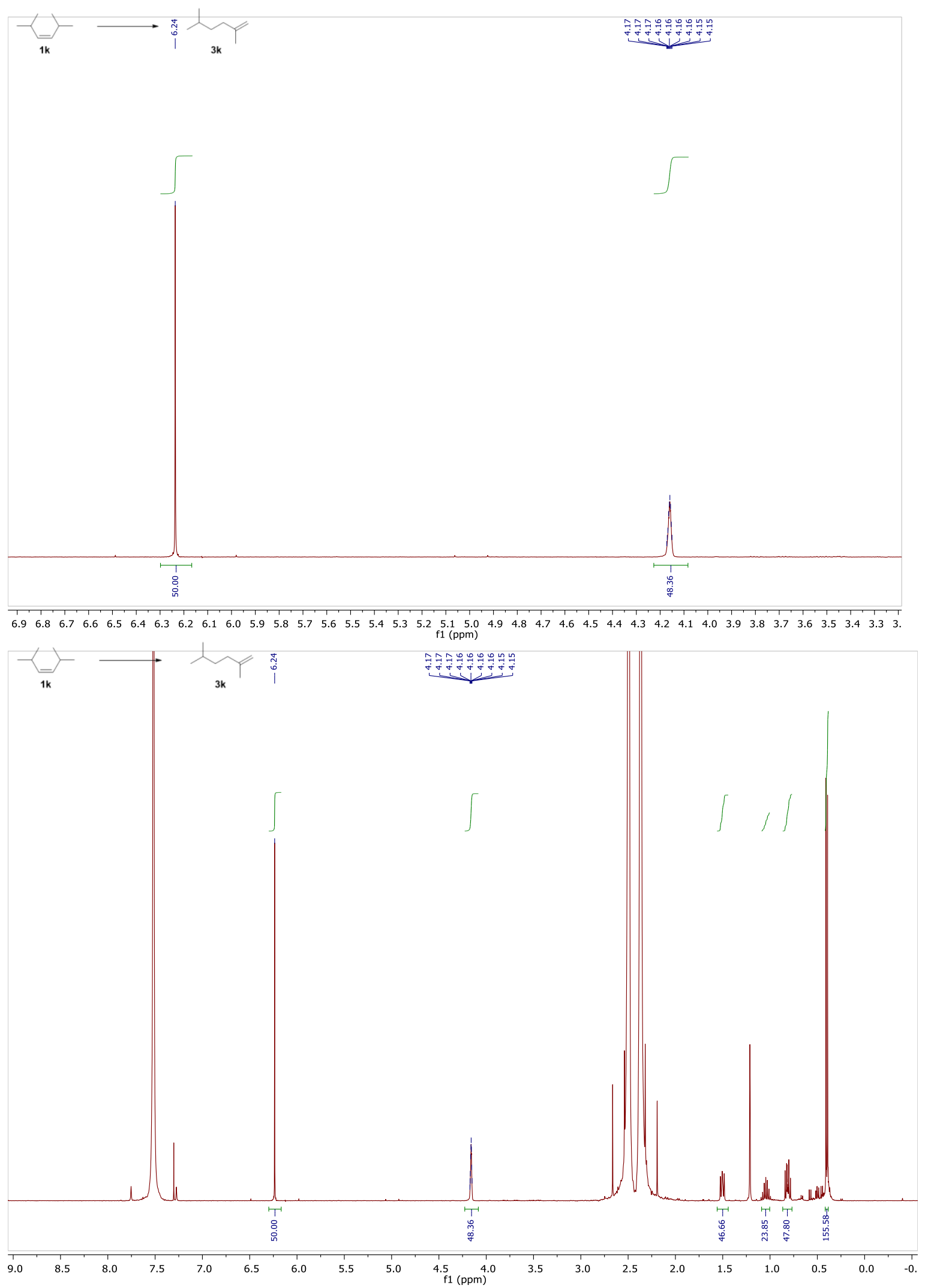




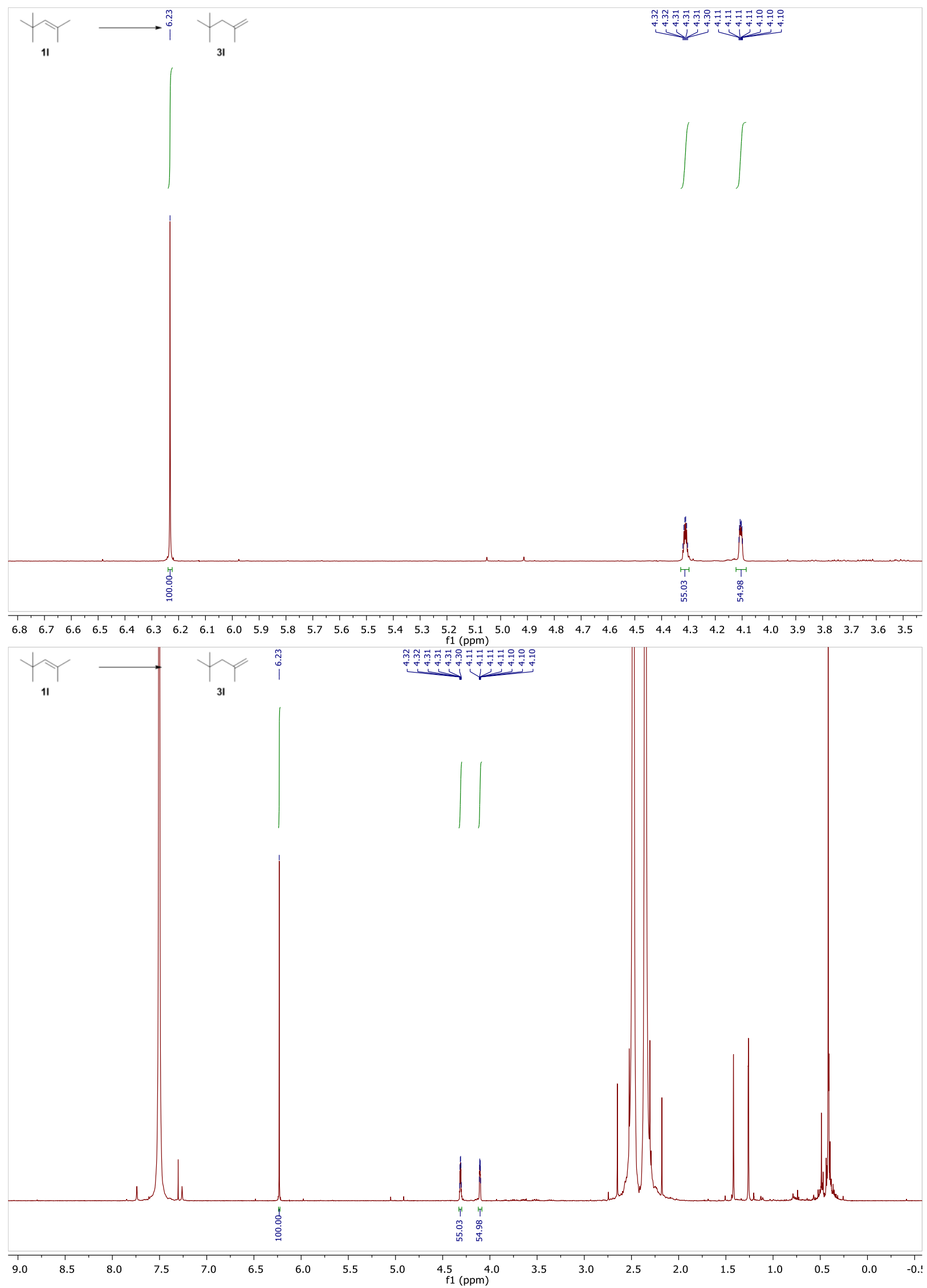




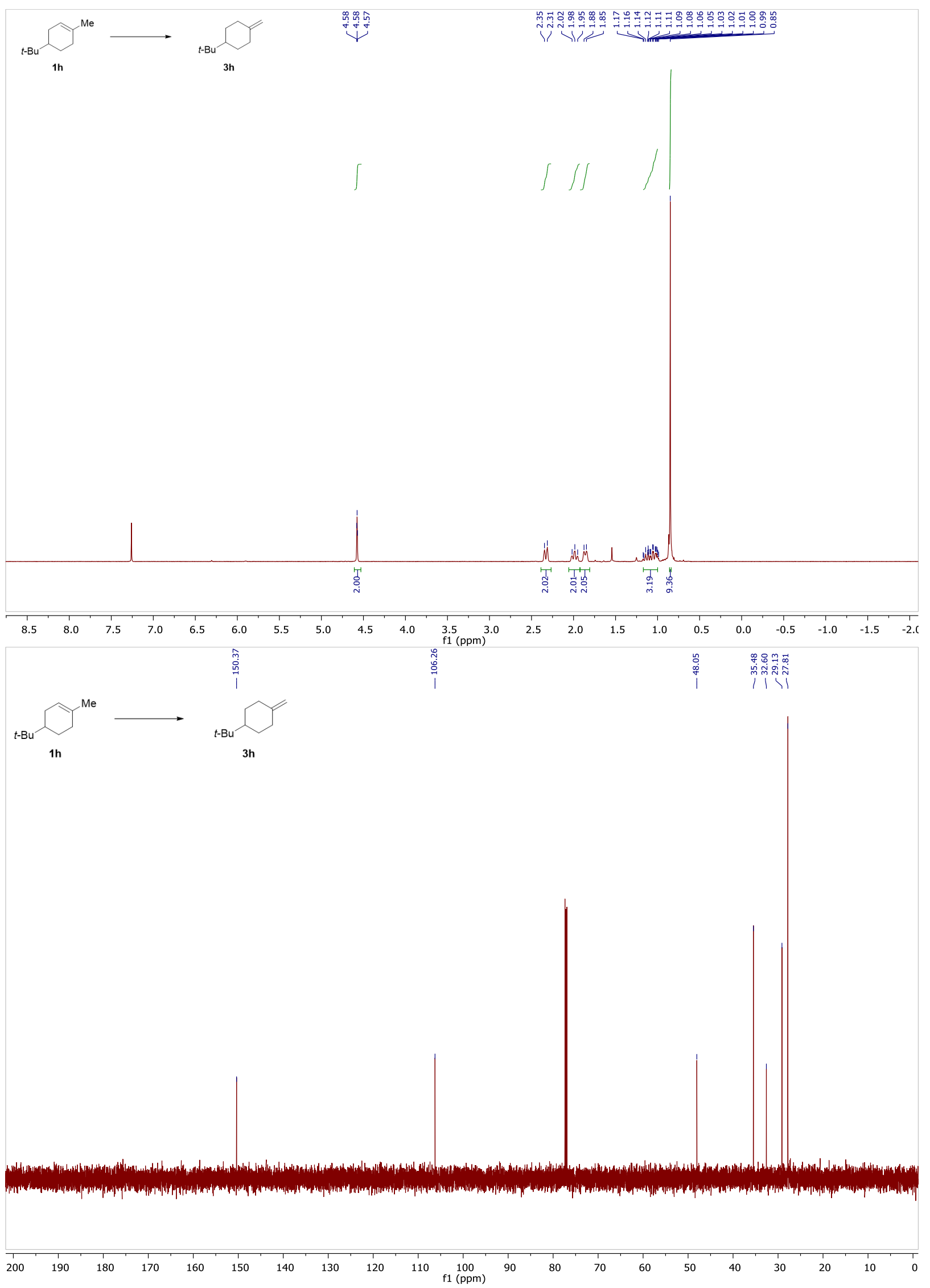

